\title{
MOLECULAR CHARACTERISATION OF AIRPORT MALARIA: FOUR CASES IN FRANCE DURING SUMMER 1999
}

\author{
JAFARI S.*, DURAND R.*, LUSINA D.** \& LE BRAS J.*
}

\section{Summary :}

Four airport malaria cases have been observed in the vicinity of the Roissy-Charles-de-Gaulle International Airport, Paris, France. These cases were geographically very close to each other and clustered in a short period of time during the summer of 1999. The phenotype and genotype of the Plasmodium falciparum isolates obtained from these patients were determined in order to know whether a single mosquito could have infected more than one subject. The genomic characterisation of isolates was performed using the polymorphic markers merozoite surface protein 1 (Msp 1) and merozoite surface protein2 (Msp2) genes, the $\kappa$ and $\Phi$ repeats domains of $\mathrm{cg} 2$ and the dihydrofolate reductase (DHFR) genotypes. Results showed identical genotypes for isolates 1, 2 and 4 whereas the genotype of isolate 3 differed at one locus. The molecular analysis was consistent with the hypothesis that all patients could have been bitten by the same mosquito and that patient 3, may have received a different clone and an additional species. In vitro susceptibility data did not confirm or rule out this hypothesis because isolates had the same profile of susceptibility to the tested drugs.

KEY WORDS : airport malaria, Plasmodium falciparum, Plasmodium malariae, genotyping, in vitro susceptibility.
Résumé : CARACTÉRISATION MOLÉCULAIRE DE QUATRE CAS DE PALUDISME D'AÉROPORT OBTENUS EN FRANCE AU COURS DE L'ÉTÉ 1999

Quatre cas de paludisme d'aéroport ont été observés au voisinage de l'aéroport Roissy-Charles de Gaulle de Paris. Ces cas, regroupés sur une courte période de l'été 1999, étaient géographiquement très proches. Le phénotype et le génotype des isolats de Plasmodium falciparum de ces patients ont été déterminés dans le but de savoir si un seul moustique a pu infecter plus d'un sujet. Le génotypage des isolats a été effectué au moyen de l'étude des marqueurs polymorphes merozoite surface protein l (Msp l) et merozoite surface protein 2 (Msp2), des répétitions $\kappa$ et $\varpi$ du gène $\mathrm{cg} 2$, et du génotype de la dihydrofolate réductase (DHFR). Les résultats ont montré un profil moléculaire identique pour les isolats 1, 2 et 4 et un génotpye différent pour l'isolat 3 à un locus. L'analyse moléculaire est en accord avec l'hypothèse d'une contamination par le même moustique des cas 1, 2, 3 et 4 . Cependant, le cas 3 pourrait avoir reçu un clone différent et une espèce associée. L'étude de la sensibilité in vitro n'a pu infirmer ni confirmer cette hypothèse dans la mesure où les isolats ont présenté le même profil de sensibilité aux antipaludiques testés.

MOTS CLÉS : paludisme d'aéroport, Plasmodium falciparum, Plasmodium malariae, génotypage, sensibilité in vitro.

\section{INTRODUCTION}

A irport malaria is acquired through the bite of an infective Anopheles mosquito transported by aeroplanes from endemic areas (Giacomini, 1998; Guillet et al., 1998). The first two cases were retrospectively reported in a French illegitimate couple in 1969 (Doby \& Guiguen, 1981). The man and the woman lived in the same street near the Bourget airport. They had no compatible travel history; they did not receive a recent blood transfusion and did not take intravenous drugs. Both were infected by Plasmodium

\footnotetext{
* Centre National de Référence pour la Chimiosensibilité du Paludisme, Assistance Publique-Hôpitaux de Paris, Laboratoire de Parasitologie, Hôpital Bichat-Claude Bernard, 46, Rue Henri Huchard, 75877 Paris cedex 18, France.

** Laboratoire de Biologie Médicale, Centre Hospitalier Robert Ballanger, 93602 Aulnay-sous-Bois, France.

Correspondence: S. Jafari, Laboratoire de Parasitologie, Hôpital Bichat-Claude Bernard, 46, Rue Henri Huchard, 75877 Paris cedex 18, France. Tel.: +33 (0)1 40257897 - Fax: +33 (0)1 40256763 .

E-mail: cnrcp.parasit1@bch.ap-hop-paris.fr
}

falciparum. The man died and the woman recovered spontaneously. Since then, 73 other cases of airport malaria have been reported in Western Europe, 28 of which occurred in France (Lusina et al., 2000). A review of the history of the cases shows that airport malaria mostly occurred simultaneously in more than one individual in the same area (Isaacson, 1989). In many cases, the members of the same family living in close proximity to an international airport were involved as were personnel working on airstrips or in air terminals (Bouvier et al., 1990; Majori et al., 1990; Giacomini et al., 1997; Van Den Ende et al., 1998).The hypothesis of one mosquito biting more than one person has already been suggested in a previous review (Isaacson, 1989). A phenotypic and a limited molecular study of $P$. falciparum isolates was also consistent with this hypothesis for two cases observed in 1994 (Eldin de Pécoulas et al., 1996). Evidence that a same mosquito may lead to several airport malaria cases could have practical implications in terms of alert procedures and management of the relatives or colleagues of a patient. 
Four recent airport malaria cases have been observed in the vicinity of the Roissy-Charles de Gaulle International Airport, Paris, France (Lusina et al., 2000). These cases were geographically very close to each other and clustered in a short period of time during the summer of 1999. The phenotype and genotype of the $P$. falciparum isolates obtained from these patients were determined in order to know whether a single mosquito could have infected more than one subject.

\section{MATERIALS AND METHODS}

$\mathrm{V}$ enous blood samples were collected in EDTA Vacutainer $^{\circledR}$ tubes (Becton Dickinson, USA) and maintained at $4^{\circ} \mathrm{C}$. The microscopic observation of thin blood smears showed that all patients were infected with $P$. falciparum; one case (patient 3 ) presented another malaria episode due to $P$. malariae 35 days after the initial $P$. falciparum infection. Patient 1, a 30-year old man, was admitted to hospital on 27 July 1999. He had developed fever with cough and diarrhoea from 20 July. Blood smears showed 35.500 parasitized red blood cells/ $\mu$ l (parasitemia of $0.8 \%$ ). Patient 1 recovered rapidly after quinine IV treatment. Patient 2, a 29-year old woman, was admitted on 5 August, having suffered from a fever for six days. Blood smears showed 209.000 parasitized red blood cells $/ \mu \mathrm{l}$ (parasitemia of $5.5 \%$ ). Patient 2 received quinine IV and recovered. Patient 3, a 43-year old man, was hospitalised on 11 August, having suffered from a fever for a week. Blood smears showed 86.000 parasitized red blood cells/ $\mu \mathrm{l}$ (parasitemia of $2 \%$ ). The outcome was favourable under quinine IV treatment for all the four patients. Patient 3 developed a new malaria episode which was due to P. malariae as mentioned before. Patient 4 , a 25 -year old woman, consulted a physician on 30 July for digestive problems with fever. A viral infection was misdiagnosed and patient 4 was hospitalised on 28 August for fever and vomiting. A pancytopenia was observed, blood smears showed a parasitemia of $5 \%$. Patient 4 received quinine IV and recovered. The clinical presentation and epidemiological aspects of these cases have been reported in details elsewhere (Lusina et al., 2000).

Genomic DNA extraction was performed as previously described (Durand et al., 1997). The amplifications of block 2 of merozoite surface protein 1 (Msp1) and merozoite surface protein 2 (Msp2) genes were performed as previously described (Randford-Cartwright et al., 1993). Size polymorphisms of msp1 and msp2 genes PCR products were resolved on a $2 \%$ agarose gel stained with ethidium bromide. PCR products were purified using QIAQuick PCR Purification Kit ${ }^{\mathbb{B}}$ (Qiagen).
Msp1 and msp2 PCR products were then sequenced using an ABI PRISM ${ }^{\circledR} 310$ Genetic Analyser and an ABI PRISM $^{\circledR}$ Big Dye Terminator Cycle sequencing Kit $^{\circledR}$ (Perkin-Elmer Cetus). The genomic characterisation of isolates was completed by the study of the $\mathrm{cg} 2$ and the dihydrofolate reductase (DHFR) genotypes. The $\kappa$ and $\Phi$ repeats domains of $c g 2$ were amplified as previously described (Durand et al., 1999). Size polymorphisms of PCR products were resolved on a $2.5 \%$ agarose gel stained with ethidium bromide. The determination of the nature of DHFR codon 108 was performed by PCR followed by restriction fragment length polymorphism (PCR-RFLP) (Eldin de Pécoulas et al., 1995). The in vitro susceptibility to chloroquine, quinine and halofantrine of isolates was determined on patient parasitized red blood cells within three days of sampling using the semi-microtest method (Le Bras \& Deloron, 1983). The $50 \%$ inhibitory concentration $\left(\mathrm{IC}_{50}\right)$ of tritiated hypoxanthine uptake was calculated by non-linear regression analysis. The in vitro susceptibility to chloroquine was defined as $\mathrm{IC}_{50}<80 \mathrm{nM}$. Threshold values for susceptibility to quinine and halofantrine were defined respectively as $\mathrm{IC}_{50}<800 \mathrm{nM}$ and $\mathrm{IC}_{50}<6 \mathrm{nM}$.

\section{RESULTS}

T he data obtained for isolates 1,2 and 3 reflected in vitro resistance to chloroquine and susceptibility to quinine and halofantrine (Table I). The semi-microtest was a failure for the fourth isolate due to the delayed shipment of the sample.

Msp1 and msp2 PCR products showed an identical profile on the agarose gel in all the cases. All isolates were polyclonal as two bands were observed (one of the bands appeared with a higher intensity) on the msp1 and $m s p 2$ profiles. Results of DNA sequencing summarized in the Table I showed identity in block 2 repeat region of $m s p 1$ gene which belonged to the K1 allelic family for all the four isolates while the polymorphic central domain of $m s p 2$ gene showed identity in isolates 1, 2 and 4 which belonged to the 3D7/CAMP allelic family with seven repeats of the hexanucleotide GGTGCT in block 2 (Smythe et al., 1993). The polymorphic central domain of $m s p 2$ in isolate 3 was a subtype of the 3D7/CAMP allelic family with eight repeats of the hexanucleotide GGTGCT in block 2 . The $\operatorname{cg} 2 \kappa$ and $\varpi$ patterns of all the four isolates showed identical multiple bands on the agarose gel which confirmed the polyclonality observed with the $m s p 1$ and $m s p 2$ profiles. The bands corresponding to $\kappa 14$ and $\varpi 16 \operatorname{cg} 2$ repeats domains had a higher intensity. Analysis of the sequences indicated that all the isolates had the "resistant" $\varpi 16$ and $\kappa 14 \mathrm{cg} 2$ repeats 


\begin{tabular}{|c|c|c|c|c|}
\hline Characteristics & Case 1 & Case 2 & Case 3 & Case 4 \\
\hline \multicolumn{5}{|l|}{ Susceptibility (1) } \\
\hline Chloroquine & $271 \mathrm{~nm}$ & $113 \mathrm{~nm}$ & $311 \mathrm{~nm}$ & ND \\
\hline Quinine & $557 \mathrm{~nm}$ & $339 \mathrm{~nm}$ & $473 \mathrm{~nm}$ & ND \\
\hline Halofantrine & $0.88 \mathrm{~nm}$ & $1.22 \mathrm{~nm}$ & $0.92 \mathrm{~nm}$ & ND \\
\hline \multicolumn{5}{|l|}{ DHFR (2) } \\
\hline 108 & Ser & Ser & Ser & Ser \\
\hline \multicolumn{5}{|l|}{$\operatorname{cg} 2$} \\
\hline$\kappa$ repeats $(3)$ & $\kappa 14+\kappa x$ & $\kappa 14+\kappa x$ & $\kappa 14+\kappa x$ & $\kappa 14+\kappa x$ \\
\hline$\varpi$ repeats $(4)$ & $\varpi 16+\varpi x$ & $\varpi 16+\overline{\omega x}$ & $\bar{\omega} 16+\bar{x}$ & $\bar{\omega} 16+\bar{\omega} x$ \\
\hline msp1 (5) & $m s p 1^{*}$ & $m s p 1^{*}$ & $m s p 1^{*}$ & $m s p 1^{*}$ \\
\hline \multirow[t]{3}{*}{$m s p 2(6)$} & $m s p 2^{* *}$ & $m s p 2^{* *}$ & $m s p 2^{* *}$ & $m s p 2^{* *}$ \\
\hline & 7 repeats & 7 repeats & 8 repeats & 7 repeats \\
\hline & GGTGCT & GGTGCT & GGTGCT & GGTGCT \\
\hline
\end{tabular}

(1) $50 \%$ inhibitory concentrations $\left(\mathrm{IC}_{50}\right)$ in $\mathrm{nM}$. Threshold values for resistance to Chloroquine > $100 \mathrm{nM}$; Quinine > $600 \mathrm{nM}$; halofantrine $>6 \mathrm{nM}$. (ND = not determined). (2) Wild type amino acid residue associated with antifol-susceptibility is Ser108. Mutant codons associated with antifol-resistance is Asn108. (3) and (4) $\kappa 14$ and $\varpi 16$ : profiles of migration on the agarose gel were identical in all the cases and showed polyclonality. (5) msp1: the profile of migration on the agarose gel was identical in all the cases. Sequence analysis showed the same polymorphism for all the cases. (6) $m s p 2$ : the profile of migration on the agarose gel was identical in all the cases. Sequence analysis showed identity for cases 1,2 and 4 and a distinct polymorphism in case 3 .

* K1 allelic family.

** 3D7/CAMP allelic family.

Table I. - Drug susceptibility, point mutations in the DHFR gene and repeat domains of the $c g 2, m s p 1$ and $m s p 2$ genes from four airport malaria cases.

type (Durand et al., 1999). Analysis of codon 108 of the DHFR gene showed a wild type S108 codon in all four isolates.

\section{DISCUSSION}

$\mathrm{R}$ esults showed identical genotypes for isolates 1 , 2 and 4 whereas the genotype of isolate 3 differed at one locus. The molecular analysis was consistent with the hypothesis that all patients could have been bitten by the same mosquito and that patient 3, may have received a different clone and an additional species. In vitro susceptibility data did not confirm or rule out this hypothesis because isolates 1 , 2 and 3 had the same profile of susceptibility to the tested drugs. The difference between the $\mathrm{IC}_{50}$ values of cases 1 and 2 may reflect the predominance of one clone of these isolates under culture conditions. The difference in the genotype of these cases was detected by analysing the highly polymorphic sequence in $m s p 2$ gene, while analysis of $m s p 1, c g 2$ and DHFR was not contributory. We chose to amplify block 2 of the msp 1 and the $m s p 2$ genes because of their high degree of polymorphism. As previously described, block 2 of the $m s p 2$ gene has greater variability in length, amino acid content and number of repeats than that of msp1 (Smythe et al., 1991; Snewin et al., 1994). The agarose gel that we used had not a sufficient resolution to detect a length difference of six nucleotides. A poly- acrylamide gel could be used, but as different $m s p 2$ alleles may exceptionally have the same molecular weight, DNA sequencing appeared to be the best choice. The agarose gel, showed that the four isolates had extra bands for $m s p 2$ gene, indicative of polyclonal infections. However, the possibility of the absence of detection of a minority clone in DNA sequencing has to be taken under consideration. Ideally, cloning of msp2 fragments from each isolate would be required prior to the sequencing to detect all the clones existing in isolates. If the alleles found in all the four cases were identical, a unique vector would be the most likely hypothesis. On the other hand, a single oocyst may give rise to different sporozoites derived from recombination events, driving to four meiotic products of a mating in the mosquito gut. New alleles can also arise from nucleotide repeat slippage even after a selffertilization event. Different P. falciparum clones observed in different malaria cases could therefore originate from a unique vector. The $\operatorname{cg} 2 \varpi 16$ and $\kappa 14$ profiles, which are strongly associated with resistance to chloroquine, were observed for all isolates. These data were consistent with the in vitro assay showing resistance to chloroquine for the three successful assays. The polymorphism of the $\mathrm{cg} 2$ gene was previously described essentially in isolates susceptible to chloroquine. In the present study, its interest was limited. Among all the airport malaria cases reported to date, associations of two plasmodium species have now been described twice. The first one involved P. falci- 
parum and P. ovale (Giacomini, 1998). The association between P. falciparum and P. malariae has not been previously observed in an airport malaria case. The late onset of the P. malariae episode in patient 3 could be due to a longer incubation period for that species. The $P$. malariae species diagnosis was confirmed by a species-specific PCR method.

To our knowledge, only one work had previously performed genomic analysis of airport malaria isolates (Eldin de Pécoulas et al., 1996). This study suggested identity of strains originating from two patients based on their profiles on the agarose gel, but DNA sequencing was not done. Entomological studies have shown that Anopheles do not fly very far, usually five $\mathrm{km}$ from their birth place (Belding, 1965). Patient 1 lived at a distance of $2.8 \mathrm{~km}$ from the CDG airport and worked at the airport. Patients 2, 3 and 4 lived at a distance of four $\mathrm{km}$ from the CDG airport in close proximity from each other $(200 \mathrm{~m})$. Patients 2, 3 and 4 were not airport employees and did not go to the airport in the previous weeks. Imported anopheles may also be secondarily transported by motor vehicles or luggages at some distance from the airport, as it was already described (Whithfield, 1984). Climatic conditions allowed the survival of imported anopheles but were probably insufficient for a local cycle. Besides, the only potential vectors found in the Paris region are Anopheles messae and Anopheles claviger. Neither has ever been associated with P. falciparum (Giacomini et al., 1997). Moreover, it may be stressed out that native malaria had totally disappeared in the Paris region before the beginning of the $20^{\text {th }}$ century (Bruce Chwatt, 1980). Since the first descriptions in 1969, airport malaria cases are increasingly reported in Europe (Guillet $e t$ al., 1998; Lusina et al., 2000). This could reflect the growth of traffic with the airports located within an area where $P$. falciparum is actively transmitted or the limits of preventing measures. When climatic conditions are favourable, which is the case in particularly hot summers in Europe, the imported mosquitoes may remain infectious up to several weeks. Hot temperatures not only allow the survival of imported mosquitoes but also stimulate their activity. In addition, it has been shown that a mosquito infected with $P$. falciparum could discharge sporozoites even after more than 10 blood meals (Belding, 1965). A recent study in 1997, revealed airport malaria cases due to the presence of infective Anopheles in airplanes (Cimerman et al., 1997). Evidence that a single imported infectious anopheles may lead to several airport malaria cases, some of which could be fatal, is an argument to strengthen insecticidal procedures on flights at risk and to reinforce controls of flights. Every airport malaria case should be rapidly reported to health authorities in order to alert local physicians who practise in the airport area.

\section{ACKNOWLEDGEMENTS}

W e are grateful to Dr M. Liance for providing one of the isolates. We thank Dr N. J. Pieniazek for his help. This work was supported by the French Ministry of Health (Direction de la Veille Sanitaire), Zeneca Pharma, and the Agence Universitaire de la Francophonie. S.J. is supported by a WHO/TDR Research Training grant.

\section{REFERENCES}

Bouvier M., Pittet D., Loutan L. \& Starobinski M. Paludisme des aéroports : mini-épidémie en Suisse. Schweizerische Medizinische Wochenschrift, 1990, 120, 1217-1222.

BeLding D.L. Textbook of Parasitology, Appleton-centuryCroft, $3^{\text {rd }}$ edition. New-York: Meredith Publishing Company, 1965.

Bruce Chwatt L.J. \& De Zuluetta J. The rise and fall of malaria in Europe. Oxford : Oxford University Press, 1980.

Cimerman S., Barata L.C., Pignatari A.C., di Santi S. M., BranQuinho M.S., Tubaki R.M., KirShgatter K \& Burattini M.N. Malaria transmission associated with airplane travel. Brazilian Journal of Infectious Diseases, 1997, 1, 135-137.

Doby J.M. \& Guiguen C. À propos de deux cas bretons de paludisme autochtone, en réalité premiers cas français de paludisme d'aérodrome. Bulletin de la Société de Pathologie Exotique, 1981, 74, 398-405.

Durand R., Ramiliarisoa O., Sécardin Y., Eldin de Pécoulas P., Basco L.K. \& Le Bras J. DHFR gene point mutation as a predictor of Plasmodium falciparum resistance to cycloguanil in malaria cases from Africa imported to France. Transactions of the Royal Society of Tropical Medicine and Hygiene, 1997, 91, 460-461.

Durand R., Gabbett E., Delabre J.F., di Piazza J.P. \& Le Bras J. Analysis of $\kappa$ and $\bar{\omega}$ repeats of the $c g 2$ gene and chloroquine susceptibility in isolates of Plasmodium falciparum from sub-Saharan Africa. Molecular and Biochemical Parasitology, 1999, 101, 185-197.

Eldin de Pécoulas P., Basco L.K., AbDallah B., Dje M.K., Le Bras J. \& MazABRAud A. Plasmodium falciparum: detection of antifolate resistance mutation-specific restriction enzyme digestion. Experimental Parasitology, 1995, 80, 483-487.

Eldin de Pécoulas P., Basco L.K., Wilson C.M., Le Bras J. \& MAZABRAUD A. Molecular characterization of airport malaria. Journal of Travel Medicine, 1996, 3, 179-181.

Giacomini T., Axler O., Mouchet J., Lebrin P., Carlioz R., Paugam B., Brassier D., Donetti L., Giacomini F. \& VACHON F. Pitfalls in the diagnosis of airport malaria. Seven cases observed in the Paris area in 1994. Scandinavian Journal of Infectious Diseases, 1997, 29, 433-435.

Giacomini T. Paludisme des aéroports et de leurs alentours. La Revue du Praticien, 1998, 48, 264-267.

Guillet P., Germain M.C., Giacomini T., Chandre F., AKogbeto M., Faye O., Kone A., Manga L. \& Mouchet J. Origin and prevention of airport malaria in France. Tropical Medicine and International Health, 1998, 3, 700-705. 
ISAACSON M. Airport malaria: a review. Bulletin of the World Health Organization, 1989, 67, 737-743.

Majori G., Gradoni L., Gianzi F.P., Carboni P., Cioppi A. \& Aureli G. Two imported malaria cases from Switzerland. Tropical Medicine and Parasitology, 1990, 41, 439-440.

Le Bras J. \& Deloron P. In vitro study of drug sensitivity of Plasmodium falciparum: an evaluation of a new semimicrotest. American Journal of Tropical Medicine and Hygiene, 1983, 32, 447-451.

Lusina D., Legros F., Esteve V., Klerlein M. \& Giacomini T. Airport malaria: four cases in suburban Paris during summer 1999. Eurosurveillance, 2000, 5, 76-80.

Randford-Cartwright L.C., Balfe P., Carter R. \& Walliker D Frequency of cross-fertilization in the human malaria parasite Plasmodium falciparum. Parasitology, 1993, 107, 1118.

Smythe J.A., Coppel R.L., Day K.P., Martin R.K., OduOla A., KemP D.J. \& ANDERS R.F. Structural diversity in the Plasmodium falciparum merozoite surface antigen-2. Proceedings of the National Academy of Sciences of the USA, 1991, $88,1751-1755$.

Snewin V.A., Herrera M., Sanchez G., Scherf A., Langsley G. \& Herrera S. Polymorphism of the alleles of the merozoites surface antigens MSA-1 and MSA-2 in Plasmodium falciparum wild isolates from Colombia. Molecular and Biochemical Parasitology, 1991, 49, 265-276.

Van den Ende J., Lynen L., Elsen P., Colebunders R., Demey H., Depraetere K., De Schrijver K., Peetermans W.E., Pereira DE Almeida P. \& Vogelaers D. A cluster of airport malaria in Belgium in 1995. Acta Clinica Belgica, 1998, 53, 259263.

Whitfield D., Curtis C.F., White G.B., Targett G.A.T., Warhurst D.C. \& Bradley D.J. Two cases of falciparum malaria acquired in Britain. British Medical Journal, 1984, 289, 1607-1609.

Reçu le 27 août 2001 Accepté le 7 janvier 2002 